\title{
Effect of Human Resource Management on Operational Efficiency of Universities in Kenya
}

\author{
Benjamin Kimanzi Kyambo ${ }^{1 *}$, Prof. James Njihia ${ }^{2}$, Dr. Florence Muindi ${ }^{3}$ \\ 1. School of Information Science and Technology, Kisii University, P.O Box 533-90131, Tala, Kenya \\ 2. School of Business, University of Nairobi, P. O. Box 30197 - 00100 GPO Lower Kabete Campus-Lower \\ Kabete Road, Kenya \\ 3. School of Business, University of Nairobi, P.O Box 30197 - 00100GPO Lower Kabete Campus-Lower \\ Kabete Road, Kenya \\ * Corresponding E-mail: searchtripp@gmail.com
}

\begin{abstract}
Operational efficiency facilitates an organization to increase profitability, improve competitiveness, increase productivity, use freed up capacity and position business for growth and increase organizations' prospective market significance. The effects of information systems are often indirect and are influenced by environmental, organizational, technological, and human resource factors. The objective of this study was to establish the effect of human resource management on operational efficiency of universities in Kenya. Operational efficiency is defined as aligning resources with core mission and services, reducing fragmented, duplicative operations, and goal of increasing service levels of an organization To maximize organization's operational efficiency, it is paramount that more dependable means of dealing with the organizational, technological and environmental variations related with IS projects be established. Understanding how teaching, research, extension and prudent utilization of public resources allocated to universities contribute to the overall efficiency of university operations is of great importance for universities to improve their performance. Data envelopment analysis (DEA) is proven to be reliable for appropriately assessing the efficiency of university operations due to its capability of effectively handling the multiple input and output simultaneously in a given situation. This study attempted to establish whether a combination of appropriate IS and HR coupled with institutional factors may lead to enhanced operational efficiency of an organization. Given the pivotal role universities play in the development of a country, this study adapted a multi-theory paradigm to outline a socio-technical information system implementation and organizational change for improved efficiency. To achieve the overall goal, hypothesis were formulated and tested. The interaction effects and relationships of the constructs were specified using SEM diagrams comprising of measurements and models. A cross sectional survey was conducted on all the universities charted in Kenya. A census survey was employed since the total population was considered relatively low and could further be reduced by possibility of non-response. A total of 102 questionnaires were dropped to the 34 universities which had approved the request. Out of the 102 questionnaires, 70 responses were received for a response rate of 68.6 percent. On examination of the completeness of the questionnaires, 11 were found to be incomplete. To complete the missing values, a sub-group mean value replacement function and linear interpolation methods were used. To test for reliability of the individual construct items Cronbach's Alpha test was used. The results indicate that human resource management practices have a negative effect on the universities' operational efficiency in Kenya. A major implication of this study is that human resource management practices in universities be improved. Additionally, the findings have implications on the formulation and implementation of IS innovations policy.
\end{abstract}

Keywords: Operational efficiency, Human Resource Management, Data envelopment analysis

DOI: $10.7176 /$ JIEA/11-2-07

Publication date: June $30^{\text {th }} 2021$

\section{Introduction}

\subsection{Background of the study}

Operational efficiency facilitates an organization to increase profitability, improve competitiveness, increase productivity, use freed up capacity and position business for growth and increase organizations' prospective market significance (Gavrea, Ilies, \& Stegerean, 2011). Growing expectations for improved performance from tax payers on publicly funded activities has resulted in increased review by stakeholders and universities are no exceptions (McMillan \& Chan, 2006). The authors found out that when the right combination of human resource, processes and technology come together to enhance organization's efficiency, peak operational efficiency is realized. The effects of information systems are often indirect and are influenced by environmental, organizational, 
technological, and human resource factors (Petter, DeLone, \& McLean, 2008). To maximize organization's operational efficiency, it is paramount that more dependable means of dealing with the organizational, technological and environmental variations related with IS projects be established (Ashurst, Doherty, \& Peppard, 2008).

Organization operational efficiency cannot be studied in isolation. The way in which organizations respond to the rising expectations for both public and private sector performance is often dependent on the institutional and technological impacts exerted by the environment in which they function (Weerakkody, Dwivedi, \& Irani, 2009). These aspects can be discussed using the Technology-Organization-Environment (TOE) framework of Tornatzky and Fleischer (1990) which assumes a generic set of factors to predict the likelihood of organizational efficiency (Oliveira \& Martins, 2011). The framework suggests that improved organizational performance is influenced by technology development, organizational conditions, business and organizational reconfiguration, and organization environment (Lippert \& Govindarajulu, 2006).

To acknowledge technology effectiveness, technology has to be readily accepted, available and adapt well with the clients and their resulting operations (D’Ambra, Wilson, \& Akter, 2013). In the Task Technology Fit (TTF) model, improved organizational efficiency may result from technology usage (Goodhue \& Thompson, 1995). The authors suggested that the model is more explicit concerning the relationships between the concepts relating to the impact of IS on performance in organizations. The authors argued that if there is correlation between IS functionality and the task needs of users then information systems positively impact organization's efficiency. Organizational efficiency may contribute to a sustained competitive advantage of an organization. Human capital is frequently assumed to contribute to competitive advantage due to its inimitability based on its intangible, firmspecific, and socially complex nature (Hatch and Dyer, 2004). The authors concluded that organizations that use screening tests in the hiring process enjoy higher performance, presumably because they are able to identify employees with the aptitudes, attitudes, and skills that contribute to the database of organization-specific human capital. Due to their complementary nature, this study will endeavor to use the antecedents of the Technology Organization - Environment framework, Task - Technology Fit Theory and human capital theory (HCT) to try to establish if there exists a relationship between human resource management, human resource information system, institutional factors and operational efficiency in chartered universities in Kenya.

The major functions of universities are research, teaching and community service or extension. These functions call for an elaborate system of staffing the universities with appropriate skilled human capital and provision of appropriate educational resources and processes within shrinking budgets. The ever increasing enrollment of students in universities and limited funding, it is imperative for these higher learning institutions to operate at a high degree of efficiency (Kuah and Wong, 2011). The significance of effectiveness and efficiency has been widely recognized for the success of both public and private higher learning institutions in today's increasingly competitive environment (Bayraktar, Tatoglu and Zaim, 2013). Current changes in political, economic and social - cultural forces are driving change in the local higher education environment (CUE, 2017). Extant literature on performance measurement on universities (Bayraktar et al, 2013; Kuah and Wong, 2011; Dyson and Shale, 2010) mainly focused on developed countries like Australia, UK and USA. It is worthwhile to extend the study of efficiency measurement of higher learning institutions in developing countries and for this study, Kenya.

\subsection{Problem statement}

Shocks are inevitable to everyone everywhere and in the wake of shock of chronic/severe illness like Corona virus (Covid-19) which is infecting and affecting individuals worldwide and countrywide; the response may be negative or positive. The negative responses acts like additional shocks, hence focus will be on the positive responses (good reports) which are meant to counter the shocks and improve individuals and consequently household's welfare. The positive response varies in different aspects including receiving help from government, local and international non-governmental organizations (NGO). In some cases the covid-19 results to death of a household member, which calls for immediate response to the shock with stern actions like seeking spiritual help from religious institutions including prayers, sacrifices, or even consulting a diviner. During the outbreak of corona virus, many individuals have lost their employment and at such a time when loss of salaried employment or non-payment of salary results, individuals ought to positively respond to the shock by various aspects even if being deployed or starting a new business. A time like this the health care facilities are overstrained with many hospitalizations, resulting from day to day increase in the shocks (corona virus) and its associated shocks like loss of employment, business failure and death. Likewise, the governments' curfews have made individuals to limit their movements, reduce physical activity, and change their food and nutrition and as a result may negatively affect their health outcomes. 


\subsubsection{Human Resource Management}

Human resource management (HRM) refers to the use of explicit personnel management practices in an integrated manner (Syed \& Jamal, 2012). The authors observed that, HRM is an integrated and coherent use of policies and techniques such as selection, performance appraisal, reward and training to enhance organizational performance. They further emphasized that HRM should foster a business-oriented and business- integrated approach in the management of employees. Strategic significance of human resource management (HRM) or talent management in organizational plans together with organizational models underscores the central success factors of leadership and managerial objectives (Richard \& John, 2001). Hughes (2002) identified four conceptions of HRM, the traditional HRM, integrative HRM, strategic HRM and universal HRM (uHRM).

To guarantee optimum operations and outsmart competitors, organization need to formulate HRM practices associated to explicit procedures, formal strategies and viewpoints planned to draw, develop, encourage and retain employees (Tan \& Nasurdin, 2011). Employees' behavior can be affected by the strategy that management of an organization employs (Fajana et al., 2011). The authors observed that using appropriate HRM practices like strategic empowerment of a highly dedicated and accomplished manpower using a combined range of educational, structural, cultural and personnel techniques, organizations can achieve competitive edge over their competitors.

Contemporary organizations are more humane, ensuring development and education, prosperity, job security and progression of common values treating their employees as their associates (Durkovic, 2009). An organization should ensure that its employees are managed effectively, employees are appropriately qualified, postings are aligned to existing positions, and employees are regularly trained and devoted to the organization's achievement in order to remain competitive in the erratic environment. Obeidat (2012) categorized HRM functions as planning, recruitment, selection, reward management, employee relations, appraisal, union management relation, training, participation, health and safety and internal career opportunities.

\subsubsection{Operational Efficiency}

Efficiency can be measured by comparing the amount of resources used to produce a particular good(s) or service(s) and the actual amount of good(s) and/or services produced. While this seems to be a conventional way in the field of business, the efficiency of universities in Kenya has not been extensively studied and little literature exist (CUE, 2017). Operational efficiency is defined as aligning resources with core mission and services, reducing fragmented, duplicative operations, and goal of increasing service levels of an organization (Dracos et al., 2012). Operational efficiency is about segregating the main grounds of waste in operations, reduce customer complaints, executing best practices to increase performance, training and motivating employees, mapping and re-engineering processes and identifying strategies to free up cash by reducing administrative cost (Dracos et al., 2012). An organization is said to have attained operational excellence if it is realigned to rationalized operations, it has improved processes and policies and it has inculcated an environment for continuous improvement (Dracos et al., 2012). Operational efficiency leads to improved output- input ratio and availability of required services and products.

Universities perform a vital role in the development of individual countries due to their capacity for providing critically needed education and innovation. Understanding how teaching, research, extension and prudent utilization of public resources allocated to universities contribute to the overall efficiency of university operations is of great importance for universities to improve their performance (Duan and Deng, 2016). In their study on data envelopment analysis of the efficiency of Australian universities, the authors evaluated university efficiency from three perspectives including: the overall university operations efficiency, the university teaching efficiency, and the university research efficiency. Data envelopment analysis (DEA) is proven to be reliable for appropriately assessing the efficiency of university operations due to its capability of effectively handling the multiple input and output simultaneously in a given situation (Kempkes \& Pohl, 2010). Introducing criteria of rationality and economic efficiency in public and private educational institution management has become a priority with the aim of improving processes by identifying the variables with greatest impact (Cadavid, Gomez and Guijarro, 2017).

\subsubsection{Universities Chartered in Kenya}

University students' enrolment in Kenya continues to grow steadily. The total enrolment of students in 2015 was 539,749 compared to 440,840 in 2014; this represented an increase of $22 \%$ (CUE, 2017). The commission in their report on state of university education in Kenya-2016 observed that in order to achieve the Kenya's vision 2030, it is imperative for the country to invest in the training of manpower. There are 31 public universities, 6 public university constituent colleges, 18 private universities, 5 private university constituent colleges and 14 institutions with letter of interim authority (CUE, 2017) in Kenya. The core functions of universities are research, teaching and community service or extension. These functions call for an elaborate system of staffing the universities with appropriate skilled human capital within shrinking budgets. This will ensure that universities have the right 
personnel in all divisions at the precise time and at the exact numbers that are able to interact with other stakeholders although in a report by the commission for university education (CUE, 2017) on the state of university education in Kenya, it was found that $27 \%$ of all the staff with $\mathrm{PhD}$ are in public universities compared to only $9 \%$ in private universities. The same pattern was observed for members of teaching staff with masters' qualifications. This is a cause for worry as it means that there are very few academic leaders to mentor scholars in the university education sector.

\subsection{Research Problem}

Research should to be developed around an identified central problem which it seeks to find solution for and contribute an in depth understanding of the problem which will lead to an easy search of solutions (De Silva, 2010). To describe and forecast the operational efficiency of universities is a key aim of researchers and scholars in the field of higher education institutions. Existing research (Bass, Nicholson, \& Subrahmanian, 2013; Heneman \& Milanowski, 2011; Johnson \& Gueutal, 2014), established an association between HRM and operational effectiveness. However, university efficiency cannot be explained by a single variable (Duan and Deng, 2016). Johnson and Gueutal (2014) posited that successful delivery, management and support of HR depend on greater extent to evolving information systems. Extant literature on the efficiency of universities (Bamel et al., 2014; Beadles, Lowery, \& Johns, 2005; Kempkes \& Pohl, 2010; McMillan \& Chan, 2006) (Duan and Deng, 2016 were mostly conducted in developed countries of Australia, Asia, Europe, Canada and USA. Recent studies on the relationship between IS and performance (Al-Tarawneh \& Tarawneh, 2012; Gupta, 2013; Obeidat, 2012) and HRM practices and organizational performance (Khan, Azhar, \& Hayat, 2014; Wiblen, Grant, \& Dery, 2010) focused predominantly on the privately owned profit-making organizations in developed countries. Developed countries and the private sector are expected to have established HRM practices and specialized information systems and it would be prudent to undertake a study in the both private and public sectors in developing countries so as to supplement these studies.

\subsection{Objective of the study}

The objective of this study was to establish the effect of human resource management on universities' operational efficiency in Kenya.

\subsection{Value of the Study}

Research findings will be relevant not only to the universities but other organizations and Government agencies embracing technology in cognizant with institutional, environmental and organizational considerations. Recruiting the right human resource and appropriate task - technology fit will enhance operational effectiveness. This will ensure societal obligations and Government regulations are adhered to. Findings from this study will enable Universities and other organizations to streamline HR processes and reduce administrative cost; reduce HR administration and compliance costs and assist the organizations compete more effectively for global talent. Government will also benefit from improved service and access to organizational data to allow decision makers to spot trends and manage workforce more efficiently. This study is also going to make a contribution to University's HR administration in enhancing operational efficiency of the universities. To the university policy makers of both the public and private Universities, the findings of this study will likely add to the existing policy tools that may guide operational efficiency of the Universities in Kenya.

\section{Methodology}

\subsection{Philosophical Orientation}

Research philosophy categorizations such as ontology and epistemology and their conflicting applications to the quantitative-qualitative debates are a major source of dilemma to research in establishing their relevance to subject areas and discipline (Mkansi and Acheampong, 2012). The authors argued that a number of studies have used different descriptions, categorizations and classifications of research paradigms. Uddin and Hamiduzzaman (2009) observed that social research contains philosophical analysis of methodologies including realism, empiricism, positivism, idealism, rationalism, functionalism, objectivism, subjectivism, and interpretivism. These approaches can be reviewed and critiqued on the basis of ontological and epistemological assumptions.

This study followed a positivists' paradigm approach as it aimed at progressing through hypotheses and deductions, operationalization of the concepts so that they can be measured and generalize the findings through statistical method. The positivist extreme holds the opinion that realities and values are discrete and that true knowledge of phenomena exists and is quantifiable (Stile, 2003). The study argue that problem solution should follow a design of framing hypotheses, subsequently hypotheses are verified by the use of quantitative methods; this process leads 
to validation or dismissal of the hypotheses. The main ontological feature under the positivist's model is that authenticity is external to the investigator and is characterized by things in the discourse and that objects have meaning independently of any perception of investigators (Mack, 2010). The author argued that the positivism stance stems from the epistemological assumption that information is produced deductively from a theory or hypothesis and that knowledge is not biased. This study purposes to construct hypotheses and test the hypotheses statistically using the structural equation modeling (SEM). The research starts by framing hypotheses, then testing the hypotheses to either collaborate or reject them.

\subsection{Research Design}

The collection, measurement, and analysis of data inform research design. It articulates both the organization of the research problem and the strategy of investigation used to achieve empirical indication on associations of the problem. This study employed a descriptive cross - sectional survey in both public and private universities in Kenya. Descriptive cross - sectional survey is applicable where the overall purpose is to determine whether crucial relationships among variables exist at some point in time. Cross-sectional survey has been found to be robust in other relationship studies (Beadles et al., 2005; O'Sullivan \& Abela, 2007). This kind of survey was preferred in this study since some of the universities in Kenya were chartered recently. Qualitative and quantitative data was obtained from the universities, the national treasury and the commission for university education.

\subsection{Population}

The 31 public chartered universities, 18 private chartered universities and 14institutions with letter of interim authority in Kenya (CUE, 2017), form the population of interest in this study. The choice of this population is arrived based on: different task orientation, different professional training and cultural diversity. A census survey was employed since the total population was considered relatively low and could further be reduced by possibility of non-response.

\subsection{Data Collection}

Data was solicited from Human Resource directors, ICT directors and deputy vice chancellors in charge of administration or their representatives and the commission for university education. A semi structured questionnaire and an efficiency table were the main instruments for collecting data from the respondents. A single questionnaire was used to capture demographic information, HRM and a table was used to solicit quantitative data from both the commission for university and from the national treasury. The questionnaire items for the various scales are from literature sources that have studied similar constructs and variables. Survey respondents were the human resource directors, DVC (Administration) and ICT directors or their representatives. Questionnaires were managed through the drop and pick technique. Prior to dropping the questionnaire at the universities, permission was sort from the university Vice Chancellor or Deputy Vice Chancellor; similarly, consent to solicit for information from the Commission for University Education was sort from the commissions CEO.

\subsection{Data Analysis}

The vast majority of efficiency analyses for higher education institutions have employed data envelopment techniques (Kempkes \& Pohl, 2010). Due to the fact that universities are producers of at least two outputs teaching and research DEA seems to be an appropriate method. Data envelopment analysis is a non-parametric tool that produces an empirical efficient frontier given by the data provided to the model. It enables a single efficiency index per evaluated unit and generates a reference set of efficient units, with which to establish a benchmark for improving efficiency. DEA can handle multiple inputs (resources) and outputs (products), making it applicable to the educational process. The fact that it generates a single efficiency indicator facilitates analysis. Data envelopment analysis technique uses linear programming to compare production units that handle the same resource group and yield the same group of products, generating an efficient frontier and related efficiency indicators within the population of production units studied (Cadavid et al, 2017). In models of Data Envelopment Analysis (DEA), an optimal set of input and output weights is generally assumed to represent the assessed Decision Making Unit (DMU) in the best light in comparison to all the other DMUs (Saati, 2008). The author further pointed out that the sets of weights are, typically, different for each of the participating DMUs and thus, it is important to find a Common Set of Weights (CSW) across the set of DMUs then use the CSW to compute relative efficiencies of DMUs. 


\section{Study Findings and Discussion of Results}

\subsection{Data Collection and Respondent Characteristics}

In administering the questionnaires, an initial request to access university information/data was send to the university Vice-Chancellors/ Deputy Vice Chancellors. Out of the 31 public universities, 26 universities approved the request, 3 did not approve citing sensitivity of information required and 2 did not respond. Approval to collect data was also secured from 7 private universities and 1 institution with LIA. After the initial request, another visit was made to the universities to drop the questionnaires. A total of 102 questionnaires were dropped to the 34 universities which had approved the request.

Out of the 102 questionnaires, 70 responses were received for a response rate of 68.6 percent. On examination of the completeness of the questionnaires, 11 were found to be incomplete. Of the 11 incomplete questionnaires, 1 was discarded as the respondent only filled the demographic items which comprised 40 percent of the total questionnaire items. The remaining 10 incomplete questionnaires were used as the respondents had answered most of the questions. The questionnaires may have not been completed due to several factors: perceived confidentiality of data, lack of understanding or reluctance of the respondents to answer a question that they thought was irrelevant to their department. To complete the missing values, a sub-group mean value replacement function and linear interpolation methods were used. After completing the missing values, the 59 questionnaires became usable. This sample size was considered adequate.

This survey was conducted in both public and private universities in Kenya. The respondents were in the departments of ICT, HR and Administration. After the pilot study, some respondents indicated that they were comfortable with the academics department as they operated in two different departments. The academics department was included in the questionnaire and a space for others was also provided. A total of 46 respondents were from public universities while 13 were from private universities. Out of the 59 respondents, 19 were from HR department, 10 from administration, 16 from ICT department, 12 were from academics. The "other" option included director of quality assurance which attracted 2 respondents.

\subsection{Human Resource Management Practices}

The respondents were asked to rank various human resources practices in terms of implementation in their universities. A list of 7 main human resource practices each with sub-sections was provided for the respondents to rank. The respondents ranked the implementation of the practices from 1 indicating the strongly disagree to 5 referring to the strongly agree. The seven different constructs were HR planning, employee selection, training and development, succession and career management, employment security, compensation and reward management, and performance management. The reliability test for human resource management based on Cronbach's Alpha, shows that all the constructs had an alpha whose values exceeded the recommended 0.7 level save for succession and career management construct whose value was 0.4849 . The succession and career management construct was excluded from the final analysis in defining human resource management.

\subsection{University Operational Efficiency Based on DEA}

Data to compute university operational efficiency were solicited from the commission for university education (CUE) and the National Treasury (Government of Kenya, 2016a, 2016b). The universities operational efficiency scores and the respective returns to scale shows that the universities which are operating at optimal efficiency were only four representing 11.76 percent of the universities. In addition, only three ( 8.82 percent) of the universities exhibited constant returns to scale. However, seven (20.59 percent) universities have increasing returns to scale, while 24 (70.59 percent) universities exhibited decreasing returns to scale.

\subsection{Human Resource Management on Universities' Operational Efficiency in Kenya}

Human capital theory (HCT) was adopted in formulating human resource management practices since it was found that it had a profound impact on a range of disciplines from economics to education and sociology (Tan \& Nasurdin, 2011). Hatch and Dyer (2004) observed that human elements of the organization are those that are capable of learning, changing, innovating and providing the creative thrust which if properly motivated can ensure increased operational efficiency of the organization.

In order to test the effect of human resource management on universities' operational efficiency in Kenya, operational efficiency (theta) variable was regressed on a latent variable for human resource management (HRM) as illustrated in the path diagram figure 1 and the structural equation model (SEM) on table 1. A coefficient of 0.304 was produced with an associated p-value of 0.0149 . Since the computed p-value is less than the critical 5 percent level of significance, it shows that HRM has a negative effect on the universities' operational efficiency in Kenya. 


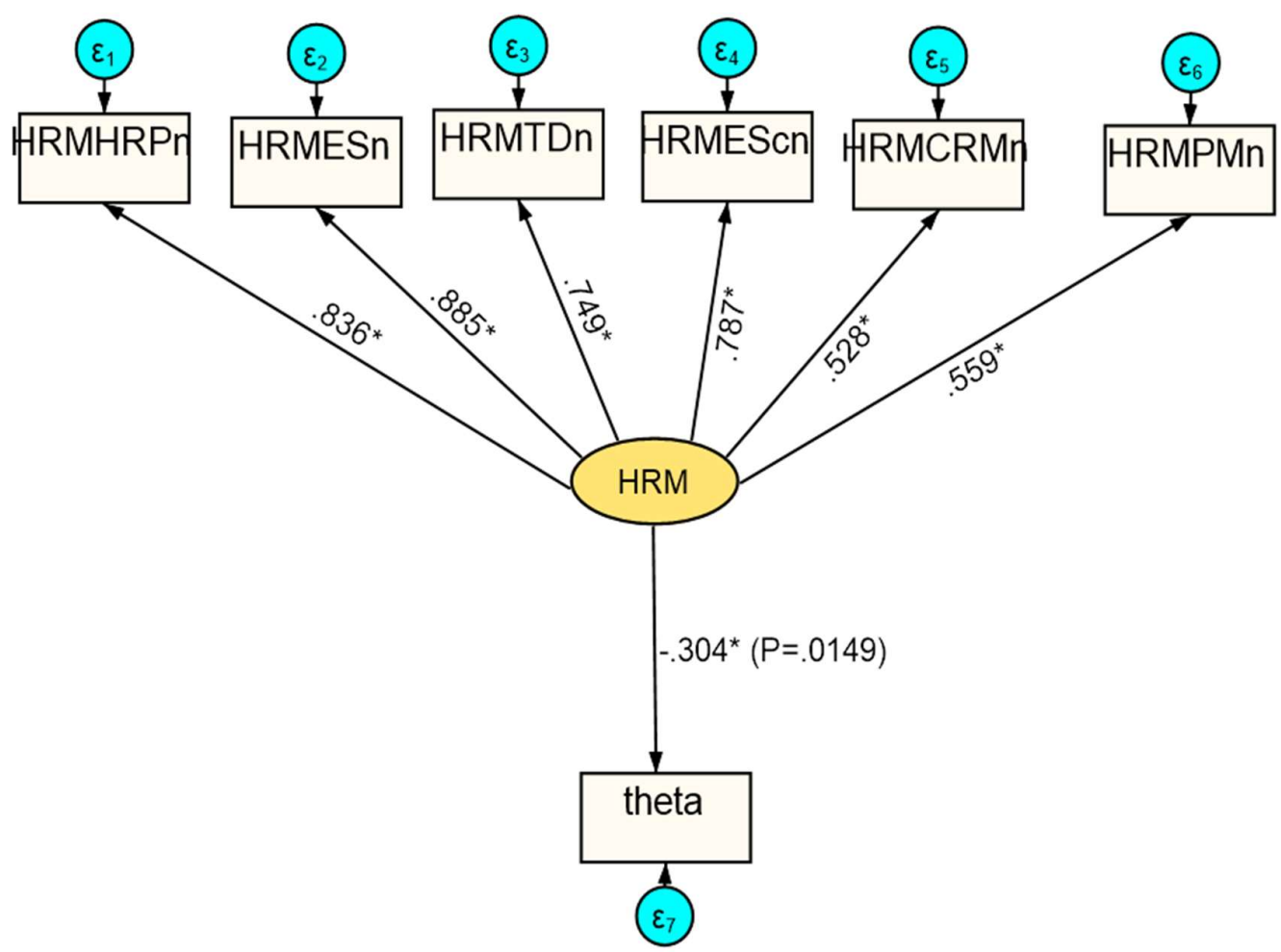

Figure 1: Human Resource Management on Universities' Operational Efficiency

The computed $p$-value $(\beta=-0.304, Z=-2.44$ and $p=0.015)$ is less than the critical 5 percent level of significance; it shows that HRM has a negative effect on the universities' operational efficiency in Kenya. This indicates that the indicators of human resource management like HR planning, employee selection, training and development, employment security, compensation and reward management, and performance management have negative influence on universities' operational efficiency. In addition, the negative influence of human resource management on operational efficiency was found to be significant.

Table 1: SEM for Human Resource Management on Universities' Operational Efficiency

\begin{tabular}{|c|c|c|c|c|c|c|}
\hline Standardized & Coef. & Std. Err. & $\mathbf{z}$ & $\bar{P}>\mathbf{Z}$ & [95\% Conf. & Interval] \\
\hline \multicolumn{7}{|l|}{ Measurement } \\
\hline \multicolumn{7}{|l|}{ HRMHRPn } \\
\hline HRM & 0.836 & 0.049 & 17.01 & 0.000 & 0.739 & 0.932 \\
\hline _cons & 4.574 & 0.441 & 10.38 & 0.000 & 3.710 & 5.438 \\
\hline \multicolumn{7}{|l|}{ HRMESn } \\
\hline HRM & 0.885 & 0.042 & 21.2 & 0.000 & 0.803 & 0.967 \\
\hline _cons & 4.420 & 0.427 & 10.35 & 0.000 & 3.583 & 5.257 \\
\hline \multicolumn{7}{|l|}{ HRMTDn } \\
\hline HRM & 0.749 & 0.066 & 11.4 & 0.000 & 0.620 & 0.877 \\
\hline _cons & 3.521 & 0.349 & 10.08 & 0.000 & 2.836 & 4.206 \\
\hline \multicolumn{7}{|l|}{ HRMEScn } \\
\hline HRM & 0.787 & 0.061 & 12.96 & 0.000 & 0.668 & 0.906 \\
\hline _cons & 4.791 & 0.460 & 10.42 & 0.000 & 3.889 & 5.692 \\
\hline \multicolumn{7}{|l|}{ HRMCRMn } \\
\hline HRM & 0.528 & 0.101 & 5.23 & 0.000 & 0.330 & 0.726 \\
\hline
\end{tabular}




\begin{tabular}{|c|c|c|c|c|c|c|}
\hline _cons & 3.550 & 0.352 & 10.09 & 0.000 & 2.861 & 4.240 \\
\hline \multicolumn{7}{|l|}{ HRMPMn } \\
\hline HRM & 0.559 & 0.098 & 5.73 & 0.000 & 0.368 & 0.750 \\
\hline cons & 4.138 & 0.403 & 10.28 & 0.000 & 3.349 & 4.927 \\
\hline \multicolumn{7}{|l|}{ theta } \\
\hline HRM & -0.304 & 0.125 & -2.44 & 0.015 & -0.549 & -0.059 \\
\hline _cons & 4.728 & 0.454 & 10.41 & 0.000 & 3.838 & 5.618 \\
\hline var(e.HRMHRPn) & 0.302 & 0.082 & & & 0.177 & 0.514 \\
\hline var(e.HRMESn) & 0.216 & 0.074 & & & 0.111 & 0.423 \\
\hline var(e.HRMTDn) & 0.439 & 0.098 & & & 0.284 & 0.681 \\
\hline $\operatorname{var}(\mathrm{e} . \mathrm{HRMEScn})$ & 0.380 & 0.096 & & & 0.232 & 0.622 \\
\hline var(e.HRMCRMn) & 0.721 & 0.107 & & & 0.539 & 0.964 \\
\hline $\operatorname{var}(\mathrm{e} . \mathrm{HRMPMn})$ & 0.688 & 0.109 & & & 0.504 & 0.938 \\
\hline var(e.theta) & 0.907 & 0.076 & & & 0.770 & 1.069 \\
\hline $\operatorname{var}(H R M)$ & 1.000 & & & & . & \\
\hline
\end{tabular}

All the indicators of human resource management; HR planning (HRMHRP), employee selection (HRMES), training and development (HRMTD), employment security (HRMESc), compensation and reward management (HRMCRM), and performance management (HRMPM) had path coefficients of 0.528 and above. The path coefficients were also significant as follows: HRMHRP ( $\beta=0.836, Z=17.01$ and $p \leqslant 0.05)$, HRMES $(\beta=0.885$, $Z=21.2$ and $p \leqslant 0.05)$, HRMTD $(\beta=0.749, Z=11.4$ and $p \leqslant 0.05)$, HRMESc $(\beta=0.787, Z=12.96$ and $p \leqslant 0.05)$, HRMCRM $(\beta=0.528, Z=5.23$ and $p \leqslant 0.05)$, and HRMPM $(\beta=0.559, Z=5.73$ and $p \leqslant 0.05)$. These results show that all the indicators of human resource management had an effect on operational efficiency in both the public and private universities in Kenya. These findings confirmed studies by Akhtar et al. (2008), Amin et al (2014) and Hassan (2016).

\section{Conclusions and Recommendations}

\subsection{Conclusions}

The objective of the study was to establish the relationship between human resource management and universities' operational efficiency. To establish if there was a relationship, operational efficiency (theta) variable was regressed on a latent variable for human resource management (HRM) and structural equation model (SEM). The results shows that human resource management practices had a negative effect on university operational efficiency ( $\beta=$ -0.304 and $p \leqslant 0.05)$. This was interpreted to imply that human resource management in both public and private universities have been disjointed and inconsistent, making it difficult for universities to make informed decisions. The respondents ranked the implementation of human resource practices (HR planning, employee selection, training and development, succession and career management, employment security, compensation and reward management, and performance management) of which succession and career management was expunged from the list. The negative relationship was insignificant and therefore the effect human resource practices on operational efficiency is still open to alternative interpretations.

To measure the effect of the constructs on operational efficiency, reliability test based on Cronbach's Alpha was first carried out. Hypothesis derived from the study objective were then tested using regression analysis. In order to test the effect of human resource management on universities' operational efficiency in Kenya, operational efficiency (theta) variable was regressed on a latent variable for human resource management (HRM). A coefficient of -0.304 was produced with an associated $p$-value of 0.0149 . Since the computed $p$-value was less than the critical 5 percent level of significance, it shows that HRM has a negative effect on the universities' operational efficiency. This is an implication that Universities in Kenya are not utilizing their workforce efficiently and this is confirms the assertion by commission for university education on the staffing ratios of teaching to non-teaching members of staff being wanting in Kenyan universities (CUE, 2017). 


\subsection{Implications of the Study}

The current study was initially driven by the call to IS researchers to not only theorize beyond the dominant but also to investigate the role of socio-cognitive factors in the adoption of IS. This study responded to this call by using human resource information system as a focal IS innovation to investigate the role of socio-cognitive factors in IS innovation implementation and University operational efficiency in Kenya. To this effect, the current study contributes to the IS theoretical inventory. The current study also contributes to the management practice especially in the area of human resource management in universities. Most of the universities that participated in this study operate in turbulent environments of reduced student enrolment and reduced capitation and for them to survive; they need to continuously seek new interpretations of the business environment. These findings provide a new knowledge that human resource management practices being applied in Kenyan universities have a negative impact on operational efficiency. These findings call for universities to revisit their staff ratios and formulate policies that may enhance proper HR practices.

\subsubsection{Theoretical Contribution}

Socio-technical theories that were used to ground this study were: the human capital theory (Tan \& Nasurdin, 2011; Troshani, Jerram, \& Hill, 2011), the technology-organization-environment (TOE) framework (Ahmad, Harun, \& Shuhaimi, 2015; Angeles, 2014; Oliveira \& Martins, 2011) and the task technology fit (TTF) model. These theories and models were used to understand and operationalize the various constructs of the study and their relationships. The constructs and their relationships were formulated into a SEM measurement and structural model. The model was then evaluated using regression analysis. The study found out that human resource management practices have statistically significant negative influence on operational efficiency in Kenyan Universities. The study confirms that human capital theory is still relevant for understanding and explaining human resource management practices being adopted by universities. All the human resource management practices had significant and positive influence on universities' operational efficiency except remuneration. Most of the studies that have employed human capital theory, TOE and TTF models to understand HRM and IS innovations were carried out in the context of developed countries, the results of this study imply that the theory and models utility extents even to the developing countries. The study therefore, contributes to the generalization of HCT, TOE framework and TTF model.

\subsubsection{Contribution of the Study to IS Body of Knowledge}

Information system body of knowledge is useful in explaining and understanding the IS artifact. The IS artifact consists of the information technology artifact, information artifact and the social artifact (Lee, Thomas, \& Baskerville, 2015). The current study contributes to the three components of the IS artifact and thus the IS body of knowledge. The study used one theory, one framework and one model to explain and understand the impact of HRM on operational efficiency. HRM practices were used to understand the community discourse about operational efficiency thus contributing to the information artifact and social artifact of IS. A model comprising of Human resource management was used to explain and understand operational efficiency in universities. The model is a representation of the IS artifact that emerges from the interaction of the IT artifact, information artifact and the social artifact.

\subsubsection{Methodological Contribution}

The results of this study provide some methodological implications. The study adapted the scales that had been used by previous studies to measure cloud computing vision, institutional forces, organizational mindfulness and firm performance. Despite the change of context, from developed countries to a developing country, all the scales passed validity and reliability tests. This is an indication that the scales are reliable regardless of context and can therefore be used in future studies for collecting data across different contexts.

The operationalization of the study variables as latent constructs was useful in understanding and breaking down the complex socio-cognitive constructs like human resource management. The use of latent variables in understanding various IS phenomena has been growing recently given that the IS artifact is socio-technical in nature. By using latent variables with reflective indicators, it was possible to make the study variables capture the day to day operations in a university (Otieno, 2013) making it easy for the respondents to understand the questions that were raised in the questionnaires.

The study employed linear regression the path analysis structural equation modeling for the analysis of the data. Path analysis SEM is widely used in IS research for simultaneously testing and estimating causal relationships among multiple independent and dependent constructs. The use linear regression was supplemented by path analysis SEM in measuring causal relationships. The estimates of the measurement and structural models of the study were important in interpreting the interplay amongst Human resource management practices, and operational 
efficiency.

\subsubsection{Implication to Policy Formulation}

Several studies have indicated many university education policy frameworks do exist in Kenya. Human resource management, government capitation and student enrolment in both public and private universities have raised some considerable concern of late. With the increasing number of higher learning institutions offering degree programs in Kenya, many ERP vendors are cashing on the information systems with capabilities of student management and human resource management. In order to ensure proper reporting, the ministry of education should put a policy framework that all these information systems should be linked with the Ministry's IS infrastructure. This will not only ensure timely reporting but also ensure compliance of universities with the tenets of the constitution of Kenya on employment and student enrolment.

The current study measured six different factors and found out that technological factors, organizational factors, task characteristics, technology characteristics, and individual characteristics affected operational efficiency of universities. The results further revealed that external task did not have an impact on operational efficiency. The Ministry of Education and by extension the government of Kenya should ensure that universities in Kenya are responsive to public expectations, adhere to their service charters by availing their services on-line and encourage e-transactions at all levels of their operations.

\subsubsection{Implications to Management Practice}

The major aim of IS research is to provide guidance to managers on whether, when, and how to innovate with IS for sustained competitive advantage. This study provides several practical implications for technology usage in universities in improving their operations. The results suggest that human resource managers should utilize information systems to improve productivity of their human resource and that university management should work closely with the government agencies and in line with the constitution in order to attract appropriate capitation and acquired human capital capable of improving operational efficiency.

The results of this study seem to suggest that universities should focus their attention and be responsive to public expectations and adhere to government policies on employment. Results from the current study indicate that when universities are recruiting, little is done to use technology so as to minimize human biasness. Though job advertisements were done electronically, short listing and interviewing was done manually reducing the advantages of using technology.

\subsection{Suggestions for Future Research}

Further research is needed to extent it to other IS innovation areas akin human resource information systems. Future research can use this study as a platform to mount new areas of research efforts relevant to academics and practitioners. In order to extend the generalizability of this study, more studies of a cross-industry and cross cultural nature need to be conducted. Such a research effort will enable the research community and industry to be better informed concerning the applicability of IST innovation theories under different institutional, economic and cultural conditions.

A cross-sectional survey study was employed in the current study due to the fact that a sizeable number of universities in Kenya were recently chartered. Although this methodology can be useful in understanding change and processes, interpreting their results depend heavily on a theoretical framework. In order to better understand constructs like human resource management practices as processes that change over time, further research should explore the use of longitudinal survey to study various IS innovation determinants and antecedents.

In this study, results revealed that human resource management practices had a negative impact on operational efficiency. This was an indication that universities were not utilizing their human resource effectively. A recent study by commission for university education revealed that staff ratios in majority of Kenyan Universities were wanting (CUE, 2017). A further study is necessary to reveal the optimum ratios required especially on non-teaching members of staff to teaching members of staff and part-time lecturers to full - time lecturers. Since this study and other extant studies have not adequately addressed the challenges faced by universities in terms of staffing levels and compliance, future studies should aim at informing the relevant policies on this matter both at the national and international levels.

\section{References}

Ahmad, Z.S, Harun, N, \& Shuhaimi, H. (2015). Using technology, organization, environment framework to investigate the determinants of the adoption of electronic publishing among Malaysian publishers. 
Australian Journal of Basic and Applied Sciences, 9(3), 37-44.

Akhtar, S, Ding, D, Z, \& Ge, G. L. (2008). Strategic HRM practices and their impact on company performance in Chinese enterprises. Human Resource Management, 47(1), 15-32. doi:10.1002/hrm.20195

Al-Tarawneh, M, \& Tarawneh, H. (2012). The effect of applying human resources information system in corporate performance in the banking sector in Jordanian firms. Intelligent Information Management, 4(2), 32-38. doi:http://dx.doi.org/10.4236/iim.2012.42005

Angeles, R. (2014). Using the technology-organization-environment framework for analyzing Nike's "Considered Index" green initiative, a decision support system - driven system. Journal of Management and Sustainability, 4(1), 96-113. doi:10.5539/jms.v4n1p96

Ashurst, C, Doherty, N. F, \& Peppard, J. (2008). Improving the impact of IT development projects: The benefits realization model. European Journal of Information Systems, 17, 352-370. doi:10.1057/ejis.2008.33

Bamel, N, Bamel, U. K, Saray, V, \& Thite, M. (2014). Usage, benefits and barriers of human resource information system in universities.VINE. The Journal of Information and Knowledge Management, 44(4), 519-536. doi:10.1108/VINE-04-2013-0024

Bass, J.M, Nicholson, B, \& Subrahmanian, E. (2013). A framework using institutional analysis and the capability approach inICT4D. Information Technology and International Develoment, 9(1), 19-35.

Beadles, N, Lowery, C. M, \& Johns, K. (2005). The impact of human resource information systems. An explanatory study in the public sector. Communication of the IIMA, 5(4), 39-46.

CUE. (2017). Commision for University Education Official website.

D’Ambra, J, Wilson, C, \& Akter, S. (2013). Application of the task-technology fit model to structure and evaluate the adoption of E-books by academics Journal of the American society for Information Science and Technology, 64(1), 48-64. Retrieved from http://ro.uow.edu.au/commpapers/3189.

De Silva. (2010). Governance Best Practice of Australian Universities. Paper presented at the Finance and Corporate Governance Conference 2010, Melbourne, Australia. http://dx.doi.org/10.2139/ssrn.1541786

Dracos, W, Huston, P, Fellouris, M, \& Patil, M. (2012). Model for operational efficiency and practice improvement. In (Vol. 13, pp. 11-12). NACUBO Internal Presentations.

Durkovic, J.V. (2009). Development of human resources strategic factors of the companies' competitive advantage. . Economics and Organization, 6(1), 59-67.

Fajana, S, Owoyemi, O, Elegbede, T, \& Sherriff, M. G (2011). Human resource practices in Nigeria. Journal of Mnagement and Strategy, 2(2), 57-62.

Gavrea, C, Ilies, L, \& Stegerean, R. (2011). Determinants of organizational performance: The case of Romania. . Management and Marketing Challenges for the Knowledge Society, 6(2), 285-300.

Goodhue, D.L, \& Thompson, R.L. (1995). Task technology fit and individual performance. MIS Quarterly, 19(2), 213-236. Retrieved from http://www.Jsator.org//stable/249689.

Government of Kenya. (2016a). Estimates of Development Expenditure 2016/2017. Nairobi: Government Printer Government of Kenya. (2016b). Estimates of Recurrent Expenditure 2016/2017. Nairobi: Government Printer

Gupta, D. (2013). Impact of computer based information systems on organizational performance in Videocon LTD. An International Journal of Engineering Sciences, 8, 36-43.

Heneman, H.G, \& Milanowski, A.T. (2011). Assessing human resource practices alignment: A case study. Human Resource Management, 50(1), 45-64. doi:10.1002/hrm.20405

Johnson, R.D, \& Gueutal, H.G (2014). Re: Leveraging HR technology for competitive advantage

Kempkes, G, \& Pohl, C. (2010). The efficiency of German universities-some evidence from nonparametric and parametric methods. Applied Economics, 42(16), 2063-2079. doi:10.1080/00036840701765361

Khan, J.N, Azhar, S, \& Hayat, Z. (2014). Strategic approach to job design: An issue in strategy implementation. International Journal of Human Resource studies, 5(1), 48-68. Retrieved from http://dx.org/10.5296/ijhrs.v5il.6794.

Lippert, S., K, \& Govindarajulu, C. (2006). Technological, organizational, and environmental antecedents to web services adoption. Communication of the IIMA, 6(1), 146-158. 
Mack, L. (2010). The philosophical underpinnings of educational research. Polyglossia, 19, 5-11.

McMillan, M, L, \& Chan, W. H. (2006). University efficiency: A comparison and consolidation of results from stochastic and non-stochastic methods. Education Economics, 14(1), 1-30. doi:1080/09645290500481857

O’Sullivan, D, \& Abela, V. A. (2007). Marketing performance measurement ability and firms performance. Journal of Marketing, 71, 79-93.

Obeidat, B. Y. (2012). The relationship between human resource information system (HRIS) functions and human resource management (HRM) functionalities. Journal of Management Research, 4(4), 192-211. Retrieved from http://dx.doi.org/10.5296/jmr.v4i4.2262. doi:10.5296/jmr.v4i4.2262

Oliveira, T, \& Martins, M. F. (2011). Literature review of information technology adoption models at firm level. The Electronic Journal Information Systems Evaluation, 14(1), 110-121. Retrieved from www.ejise.com.

Otieno, D. (2013). The role of universities in attaining Kenya vision 2030. Elixir Edu.Tech, 64, 19156-19158. Retrieved from www.elixirpublishers.com.

Petter, S, DeLone, W. H, \& McLean, E. (2008). Measuring information systems success: models, dimensions, measures, and interrelationships. European Journal of Information Systems, 17, 236-263.

Richard, O. C, \& John, N. B. (2001). Strategic human resource management effectiveness and firm performance International Journal Human Resource Management, 12(2), 299-310.

Stile, J. (2003). A philosophical justification for a realist approach to strategic alliance research. Quantitative Market Research: An Internal Journal, 6(4), 263-271.

Tan, C. L, \& Nasurdin, A. M. (2011). Human Resource management practices and organizational innovation: Assessing the mediating role of knowledge management effectiveness. Electronic Journal of Knowledge Management, 9(2), 155-167.

Troshani, I, Jerram, C, \& Hill, S. R. (2011). Exploring the public sector adoption of HRIS. Industrial Management \& Data Systems, 111(3), 470-488.

Weerakkody, V, Dwivedi, Y. K, \& Irani, Z. (2009). The diffusing and use of institutional theory: A crossdisciplinary longitudinal literature survey. Journal of Information Technology, 24, 354-368.

Wiblen, S, Grant, D, \& Dery, K. (2010). Transitioning to a new HRIS: The reshaping of human resources and information technology talent. Journal of Electronic Commerce Research, 11(4), 251-267. 